Groove depth measurements on roughness reference standards of the Croatian National Laboratory for Length (LFSB)

To cite this article: Gorana Barši et al 2011 Meas. Sci. Technol. 22094020

View the article online for updates and enhancements.
Related content

- Development of nano-roughness
$\frac{\text { calibration standards }}{\text { Gorana Barši, Sanjin Mahovi and Hrvoje }}$
Zorc
- Developments at PTB in nanometrology
for support of the semiconductor industry
Harald Bosse and Günter Wilkening
- Bilateral comparison of $25 \mathrm{~nm}$ pitch
nanometric lateral scales for metrological
Scanning probe microscopes
Ichiko Misumi, Gaoliang Dai, Mingzi Lu et
al.

Recent citations

Development of nano-roughness
$\frac{\text { calibration standards }}{\text { Gorana Barši et al }}$ 


\title{
Groove depth measurements on roughness reference standards of the Croatian National Laboratory for Length (LFSB)
}

\author{
Gorana Baršićc $^{1}$, Sanjin Mahović ${ }^{1}$, Gian Bartolo Picotto ${ }^{2}$, \\ Mohamed A Amer ${ }^{3}$ and Biserka Runje ${ }^{1}$ \\ ${ }^{1}$ Faculty of Mechanical Engineering and Naval Architecture, I. Lučića 1, 10000 Zagreb, Croatia \\ 2 Istituto Nazionale di Ricerca Metrologica, Strada delle Cacce 73, 10135 Torino, Italy \\ ${ }^{3}$ National Institute of Standards, Tersa St-El Haram-Giza, 12211 Egypt \\ E-mail: gorana.barsic@fsb.hr
}

Received 9 January 2011, in final form 24 May 2011

Published 8 August 2011

Online at stacks.iop.org/MST/22/094020

\begin{abstract}
In the Laboratory for Precise Measurements of Length, LFSB, which is now the Croatian National Laboratory for Length, unique roughness reference standards were developed in the year 1986. Because of the world-class quality of those standards and their measuring features, the same were sold in several European countries, and today they, among others, are used as roughness reference standards in Italy, Slovenia and Croatia. However, especially in the last decade, there was significant progress in the field of nanotechnology that led to the development of new measuring equipment. The above-mentioned standards due to their size, production technology and measuring features cannot fully meet metrological requirements in the field of nanometrology, i.e. they are not compatible with scanning probe microscopes. Therefore, it was decided to search for possible limitations in the procedure of groove depth measurements on the LFSB standards. In order to include as many measuring devices as possible, i.e. measurement methods, in this research, in 2008 the LFSB launched EURAMET Project 1012 'Limitations of methods for measuring the depth of the groove' in collaboration with national metrology institutes of Italy and Egypt. In this paper the results of measurements performed within the project are presented, and based on the obtained results, the advantages and limitations of the LFSB standards have been discussed, with recommendations for their improvement.
\end{abstract}

Keywords: nanometrology, roughness standards, reproducibility

(Some figures in this article are in colour only in the electronic version)

\section{Introduction}

In the last two decades there has been significant development of measuring equipment in the area of surface metrology, particularly the development of scanning probe microscopes (SPMs). Manufacturers of measuring equipment supply, along with the instrument, standards that are designed specifically for that measuring device, in order to verify the accuracy and to perform calibration of that instrument. In addition, in the market there are several manufacturers of standards in the field of dimensional nanometrology. In general, these standards are intended for individual groups of measuring instruments, such as interferometric microscopes, stylus instruments, scanning electron microscopes (SEMs) or SPMs. In the field of micrometrology the requirements for the reference standards are defined in standard [1] in their function, but not in their size.

The above-mentioned standards set the foundation of standardization in the field of micrometrology, while the assured traceabilities are accompanied by the adopted levels of measurement uncertainties. However, in the area of nanometrology further intensive work and research 


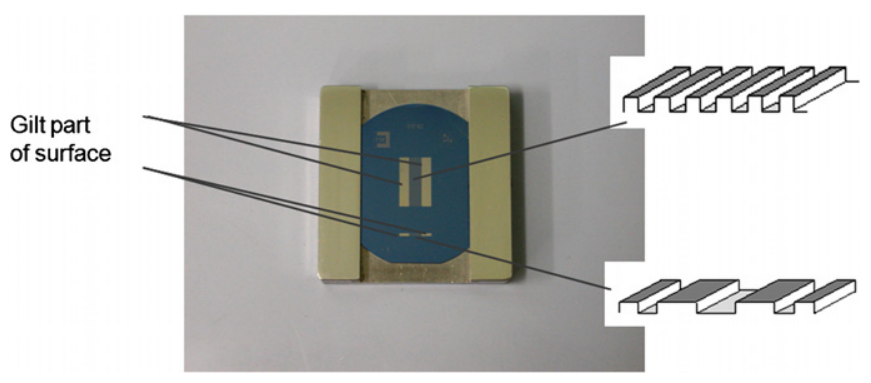

Figure 1. Roughness reference standard LFSB.

is necessary in order to introduce standardization, and respectively ensure traceability and measurement unity at the global level.

Since 1986 the LFSB has used roughness reference standards which are designed in the LFSB, and in cooperation with the company 'RIZ', Zagreb standards have been realized. The uniqueness of those calibration standards lies in two measurement surfaces. One is used for the reproduction of roughness parameters, while the other serves for traceability of the length unit.

For many years, these standards were applicable as calibration standards for all measuring equipment that measures surface roughness. However, due to significant development of measuring equipment in the field of dimensional nanometrology, the measuring features of LFSB calibration standards are no longer sufficient, especially in terms of the required levels of measurement uncertainties in the groove depth measuring procedure.

\section{LFSB roughness reference standards}

LFSB calibration standards were made from silicon monocrystal processed by planar technology, by means of which rectangular grooves in the $\mathrm{SiO}_{2}$ layer were obtained [2].

Calibration standards have two measurement surfaces (figure 1):

- surface with the grid of repetitive $\mathrm{SiO}_{2}$ rectangular grooves;

- surface with three wide $\mathrm{SiO}_{2}$ rectangular grooves.

The measurement surface with the grid of repetitive $\mathrm{SiO}_{2}$ rectangular grooves (figure 2) serves for the reproduction of roughness parameters that are defined in standard [3].

The measurement surface with three wide $\mathrm{SiO}_{2}$ rectangular grooves (depth measurement standard Type A1, according to ISO 5436-1:2000) is positioned within the rectangle bordered by a narrow furrow. This surface is presented in figure 3 .

Parts of measurement surfaces are coated with a thin layer of gold in order to ensure conditions for interferometric measurement. The calibration standards are realized in such a way that the groove depth can be measured by a contact method, usually by stylus instrument, as well as by an absolute, interferometric method. Indirectly, using the polarization method, by measuring the thickness of the $\mathrm{SiO}_{2}$ layer one can obtain the information about the groove depth [3].

However, given the fact that for measurements of groove depths one must use differently produced measurement surfaces, with respect to different measurement methods, there
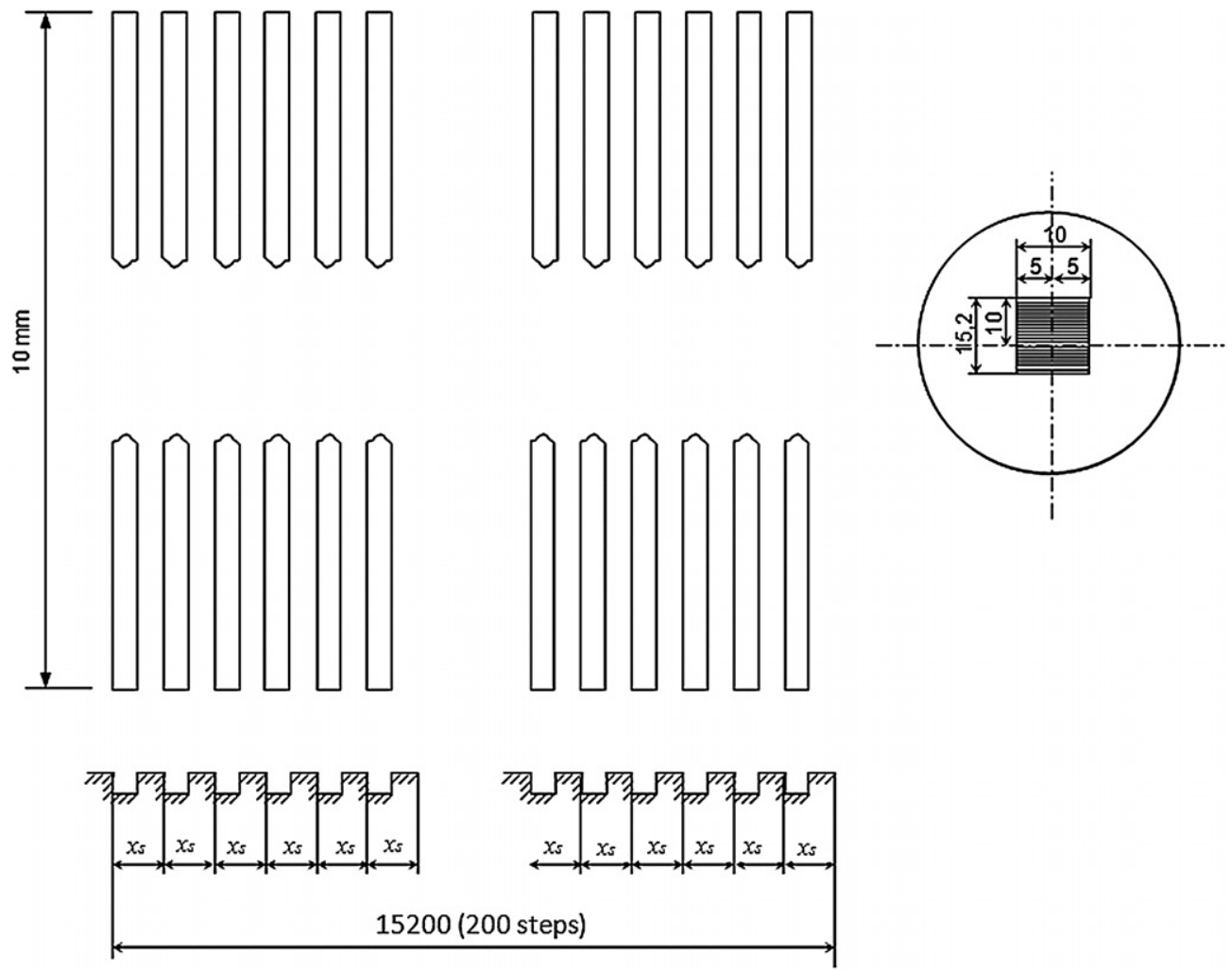

Figure 2. Measurement surface with the grid of repetitive rectangular grooves. 

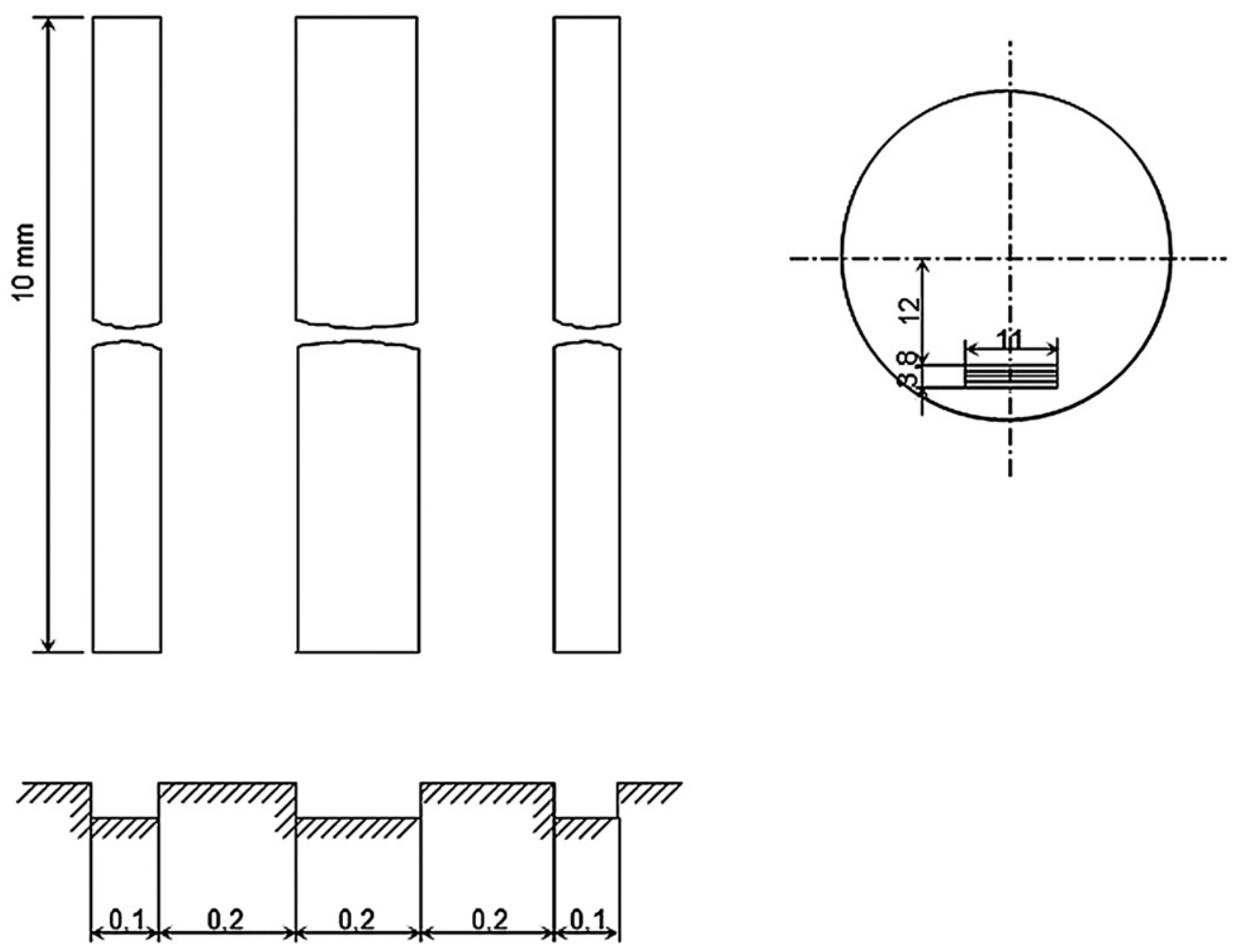

Figure 3. Measurement surface with three wide rectangular grooves.

is a question of the influence of these varied surfaces on the obtained measurement results.

Due to difficulties in ensuring the conditions for reproducibility of the results obtained with different measurement methods, and the fact that in the last two decades there has been significant development of measuring equipment in the area of nanometrology, it was decided to determine the value of variations in groove depth measurements using various available measurement methods. In order to involve as many as possible measuring instruments in this research, the LFSB initiated EURAMET Project 1012, 'Limitations of methods for measuring the depth of the groove', with national metrology institutes from Italy and Egypt as partners in research.

\section{Results of EURAMET Project 1012}

The measurements were performed on seven calibration standards with different nominal depths of grooves: 100, 240, $860,1600,2100,2700$ and $4100 \mathrm{~nm}$. As already noted the participants in these measurements were national metrology institutes of Italy (INRIM), Egypt (NIS) and Croatia (LFSB), and as an associate participant Institute Ruder Boskovic (IRB) from Zagreb, Croatia. Table 1 gives a brief review of the measurement methods, used measuring instruments, ways of ensuring traceabilities and the sizes of sampling areas and sampling lengths.

The obtained measurement results, with expanded uncertainties expressed by the coverage factor $k=2, P=$ $95 \%$, are shown in table 2 .
Figures 4-10 show the measurement results separately for each groove depth standard.

\section{Evaluation of comparison data}

From the results given in table 2 evaluation of reference values (RV) for simple arithmetic mean ( $S$-mean), inversevariance weighted mean ( $W$-mean) and median for each measured groove depth standard has been done. The results are reported in table 3 . The standard uncertainty associated with the weighted mean is evaluated using a recognized formula [4].

Some deviations occurred in the results obtained with an AFM (atomic force microscope). In comparison to the results obtained using other measuring instruments, the results obtained using the AFM showed a linear reduction while increasing the nominal values of the measured groove depths. This linear reduction function is expressed on the graph presented in figure 11.

On the horizontal axis are the calculated weighted means for each measured standard. The weighted means were calculated using the expression from the literature [4]. In the calculation of the weighted means all measurement results from table 2 were included with the exception of the results obtained using the AFM. The occurring deviations could mean that the vertical axis is not well calibrated during the selfcalibration process of the AFM.

Since the expressed means of the results obtained using the AFM showed significant deviation, they were excluded from further data evaluation. 


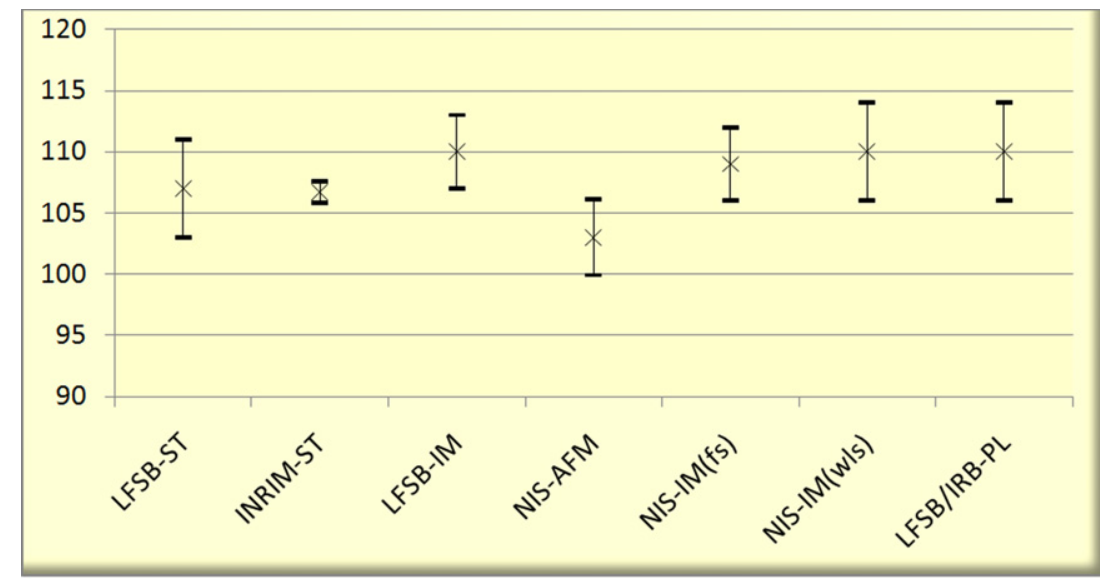

Figure 4. Measurement results for the $100 \mathrm{~nm}$ groove depth.

Table 1. Participants, measurement methods, instruments and traceability.

\begin{tabular}{|c|c|c|c|c|}
\hline Institute & Principle & Instrument & Traceability & $\begin{array}{l}\text { Sampling } \\
\text { area/length }\end{array}$ \\
\hline \multirow[t]{2}{*}{ LFSB } & ST & Stylus instrument Perthometer C5D & Calibrated using certificated artifacts & $600 \mu \mathrm{m}$ \\
\hline & $\mathrm{IM}$ & $\begin{array}{l}\text { Epival-Interphako interferometric } \\
\text { microscope }\end{array}$ & Ion stabilized $\mathrm{He}-\mathrm{Ne}$ laser & $150 \mu \mathrm{m} \times 150 \mu \mathrm{m}$ \\
\hline LFSB-IRB & PL & Ellipsometer AutoEL IV & Calibrated using certificated artifacts & $31415 \times 10^{6} \mu \mathrm{m}^{2}$ \\
\hline INRIM & ST & Stylus profilometer Talystep 1 & $\begin{array}{l}\text { Precise displacement actuator } \\
\text { calibrated using an interferometer }\end{array}$ & $270 \mu \mathrm{m}$ \\
\hline \multirow[t]{3}{*}{ NIS } & SPM & $\begin{array}{l}\text { AFM Thermomicroscope } \\
\text { Autoprobe CP }\end{array}$ & $\begin{array}{l}\text { Self-calibration by the manufacturer } \\
\text { procedure }\end{array}$ & $5 \mu \mathrm{m} \times 5 \mu \mathrm{m}$ \\
\hline & IM-wls & $\begin{array}{l}\text { Zygo NewView } 200 \text { Interferometer } \\
\text { (white light scanning) }\end{array}$ & $\begin{array}{l}\text { Calibrated using certificated step } \\
\text { height artifacts }\end{array}$ & $250 \mu \mathrm{m} \times 350 \mu \mathrm{m}$ \\
\hline & $\mathrm{IM}-\mathrm{fs}$ & $\begin{array}{l}\text { Zygo NewView } 200 \text { Interferometer } \\
\text { (phase shifting) }\end{array}$ & $\begin{array}{l}\text { Calibrated using certificated step } \\
\text { height artifacts }\end{array}$ & $250 \mu \mathrm{m} \times 350 \mu \mathrm{m}$ \\
\hline
\end{tabular}

Table 2. The results of measuring the groove depths.

\begin{tabular}{|c|c|c|c|c|c|c|c|c|}
\hline Nominal depth (nm) & & LFSB-ST & INRIM-ST & LFSB-IM & LFSB-IRB & NIS-IM (fs) & NIS-IM (wls) & NIS-AFM \\
\hline \multirow[t]{2}{*}{100} & $d$ & 107 & 106.7 & 110 & 110 & 109 & 110 & 103 \\
\hline & $U$ & 4 & 0.9 & 3 & 4 & 3 & 4 & 3.1 \\
\hline \multirow[t]{2}{*}{240} & $d$ & 242 & 242.1 & 240 & 240 & 244 & 242 & 228 \\
\hline & $U$ & 5 & 1.1 & 4 & 4 & 2 & 5 & 3.9 \\
\hline \multirow[t]{2}{*}{860} & $d$ & 856 & 861 & 860 & 857 & 859 & $\mathrm{a}$ & 790 \\
\hline & $U$ & 8 & 2.6 & 4 & 4 & 9 & & 2.3 \\
\hline \multirow[t]{2}{*}{1600} & $d$ & 1654 & 1656.2 & 1660 & 1652 & 1658 & 1659 & 1477 \\
\hline & $U$ & 16 & 4.8 & 6 & 12 & 6 & 9 & 8.2 \\
\hline \multirow[t]{2}{*}{2100} & $d$ & 2166 & 2167 & 2167 & 2153 & 2170 & 2170 & 1888 \\
\hline & $U$ & 21 & 5.6 & 10 & 13 & 12 & 10 & 19.3 \\
\hline \multirow[t]{2}{*}{2700} & $d$ & 2736 & 2739.4 & 2731 & 2730 & 2738 & 2734 & 2327 \\
\hline & $U$ & 27 & 6.3 & 10 & 13 & 8 & 10 & 65 \\
\hline \multirow[t]{2}{*}{4100} & $d$ & 4149 & 4155.1 & 4167 & 4139 & 4146 & 4166 & 3298 \\
\hline & $U$ & 41 & 10 & 10 & 15 & 26 & 36 & 45.3 \\
\hline
\end{tabular}

${ }^{\text {a }}$ Standard was not measured.

Given that all the results, besides those excluded, have the same mean statistically speaking, the classical chi-squared test was used to address the question of metrological equivalence. Namely, the task was to prove that the dispersion of results is adequately described by the measurement uncertainties stated by the participants.
Table 4 shows the calculated values for $\chi_{\text {obs }}^{2}$ and $\operatorname{Pr}\left\{\chi^{2}(\nu)>\chi_{\text {obs }}^{2}\right\}$ using the participant data given in table 2 as the source.

The obtained measurement results showed overall good comparability within the declared levels of measurement uncertainties, with the exception of the results obtained with the AFM. 


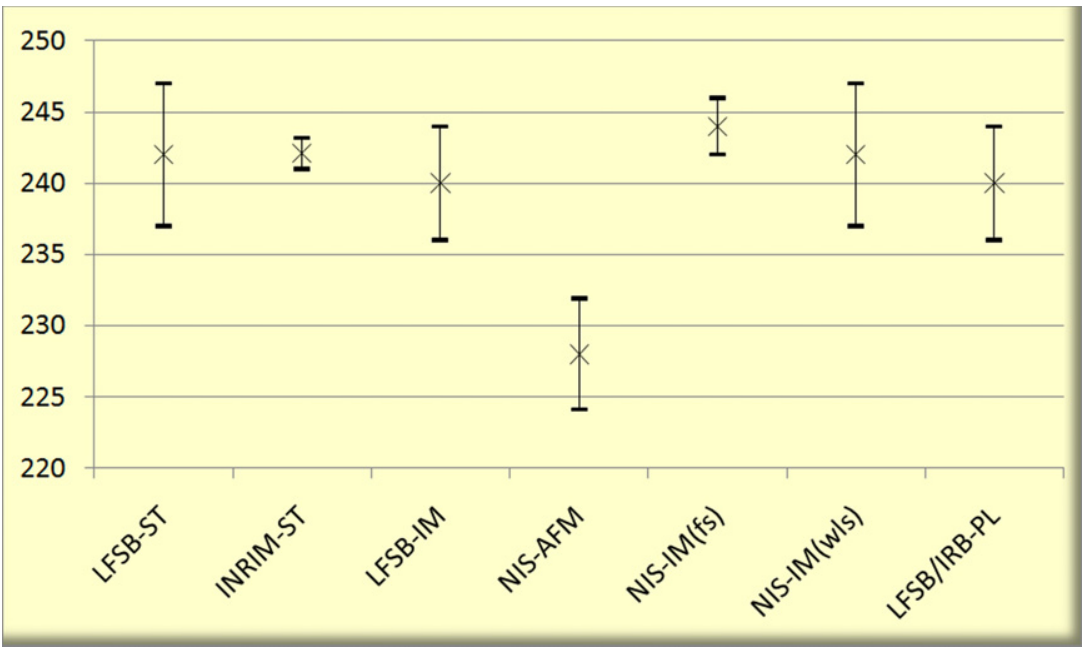

Figure 5. Measurement results for the $240 \mathrm{~nm}$ groove depth.

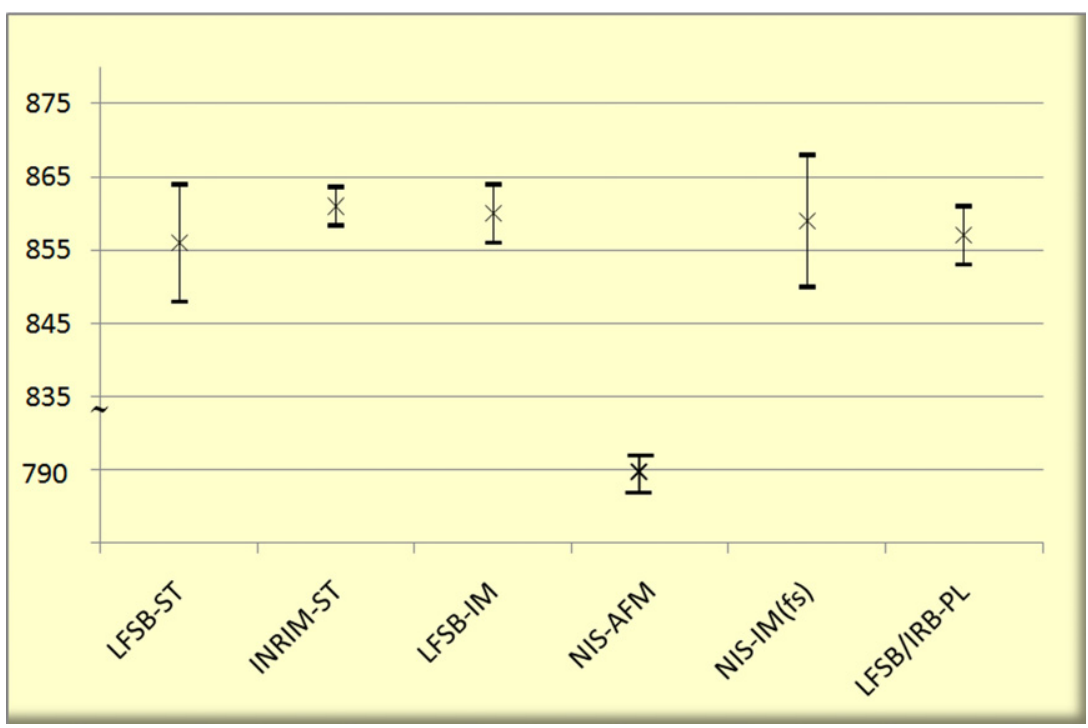

Figure 6. Measurement results for the $860 \mathrm{~nm}$ groove depth.

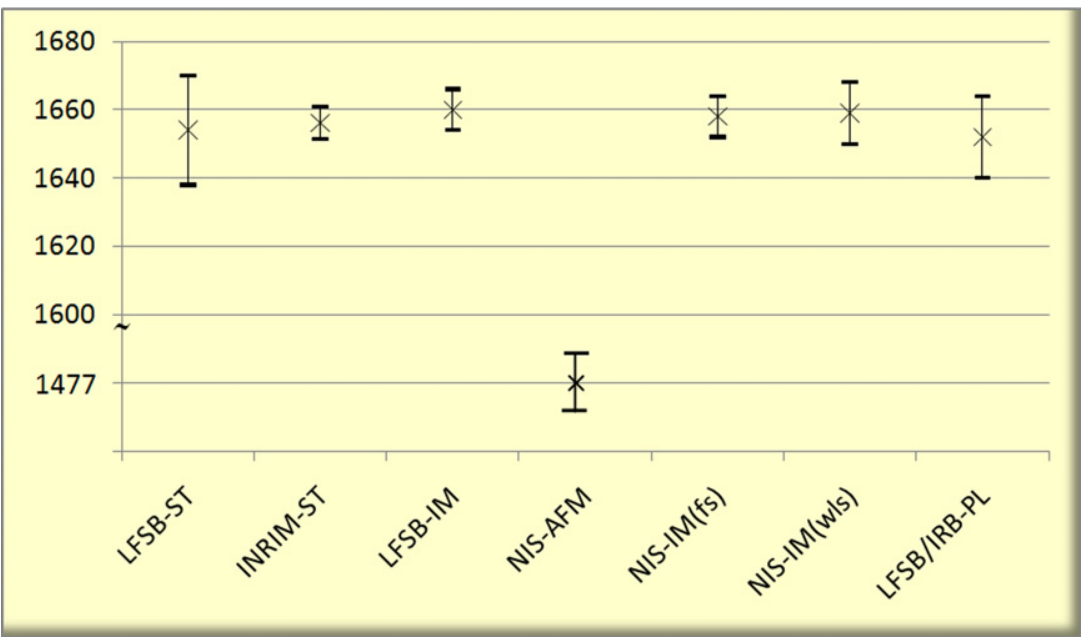

Figure 7. Measurement results for the $1600 \mathrm{~nm}$ groove depth. 


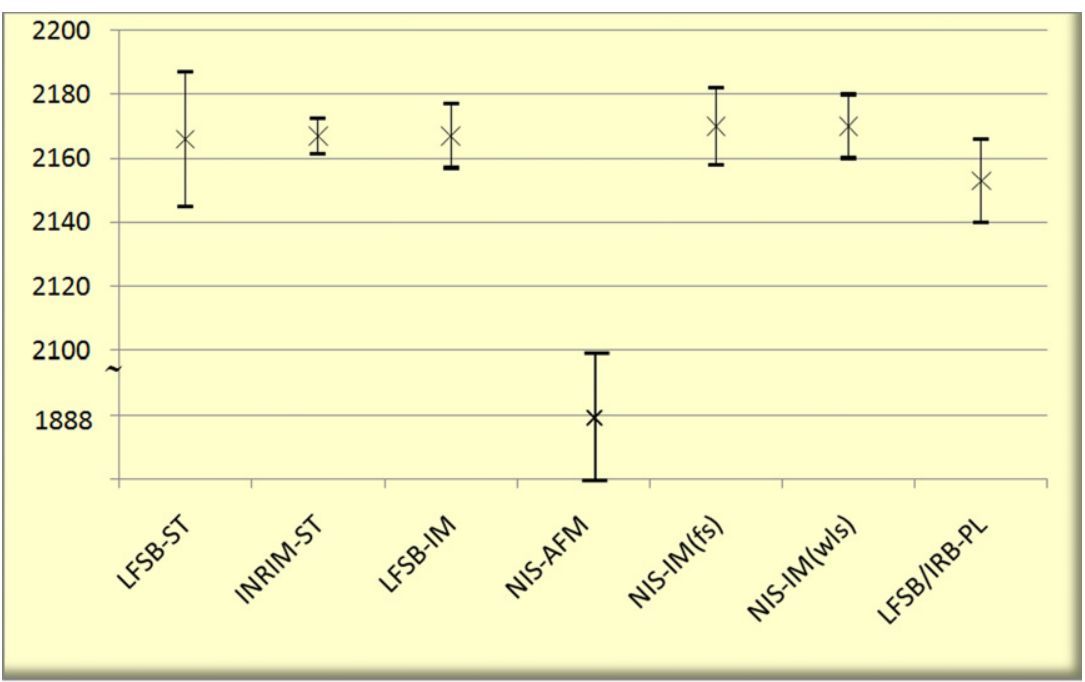

Figure 8. Measurement results for the $2100 \mathrm{~nm}$ groove depth.

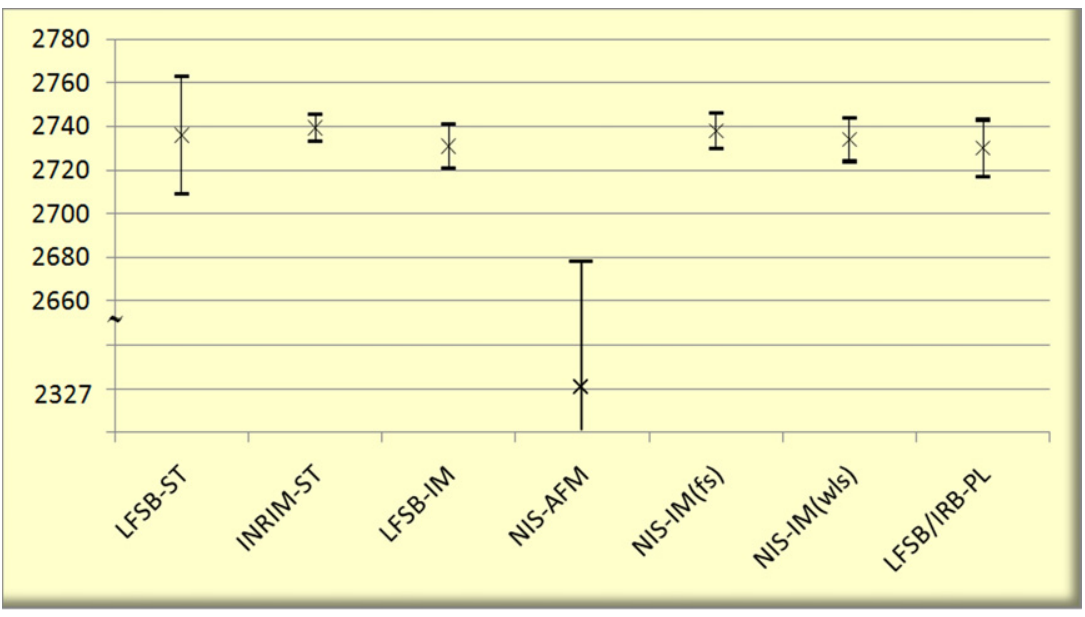

Figure 9. Measurement results for the $2700 \mathrm{~nm}$ groove depth.

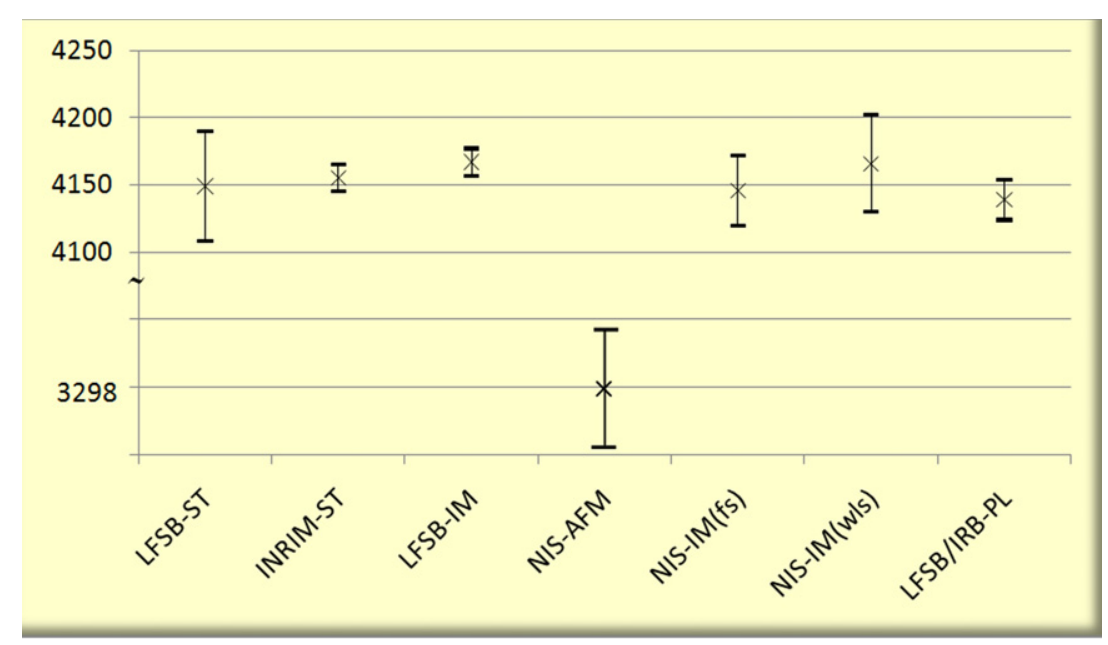

Figure 10. Measurement results for the $4100 \mathrm{~nm}$ groove depth.

If we consider the measurement areas with respect to the measurement methods used, one can see that they are prepared using different technologies (figure 12). Therefore, there is a question of the influence of various measurement surfaces on the measurement results obtained with different measurement methods. 


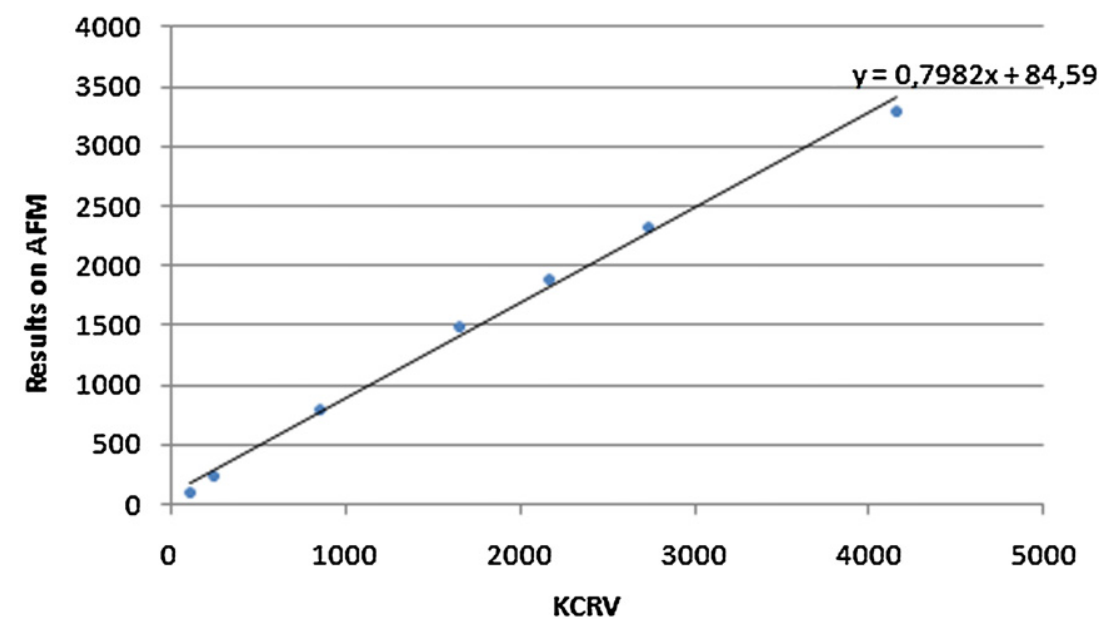

Figure 11. Observed linear reduction of the results obtained using an AFM.

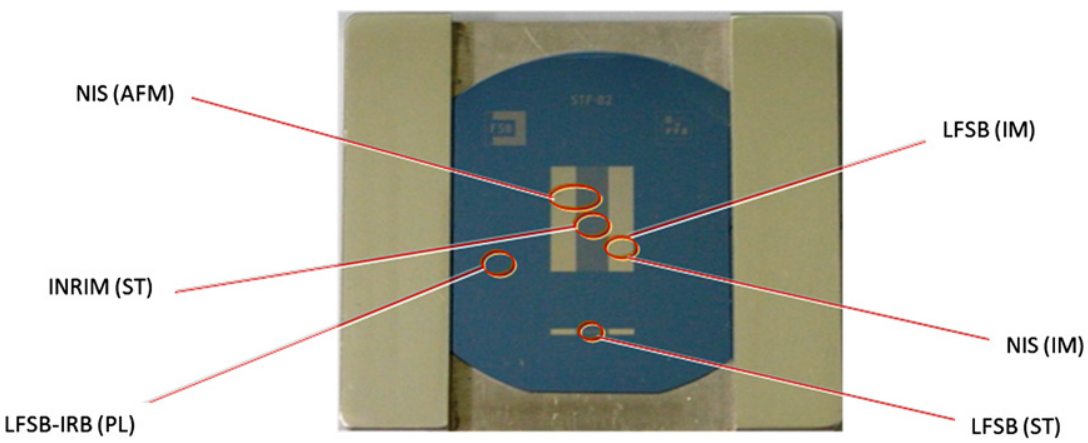

Figure 12. Measurement areas.

Table 3. The results of RV for simple arithmetic mean ( $S$-mean), inverse-variance weighted mean ( $W$-mean) and median.

\begin{tabular}{|c|c|c|c|c|c|c|}
\hline \multirow[b]{2}{*}{$\begin{array}{l}\text { Groove } \\
\text { depth (nm) }\end{array}$} & \multicolumn{2}{|r|}{$S$-mean } & \multicolumn{2}{|c|}{$\mathrm{RV} W$-mean } & \multicolumn{2}{|r|}{ Median } \\
\hline & $\begin{array}{l}\text { Value } \\
(\mathrm{nm})\end{array}$ & $\begin{array}{l}\text { Standard } \\
\text { uncertainty }(\mathrm{nm})\end{array}$ & $\begin{array}{l}\text { Value } \\
(\mathrm{nm})\end{array}$ & $\begin{array}{l}\text { Standard } \\
\text { uncertainty }(\mathrm{nm})\end{array}$ & $\begin{array}{l}\text { Value } \\
\text { (nm) }\end{array}$ & $\begin{array}{l}\text { Standard } \\
\text { uncertainty }(\mathrm{nm})\end{array}$ \\
\hline 100 & 108 & 0.6 & 107 & 0.4 & 109 & 0.6 \\
\hline 240 & 240 & 0.7 & 242 & 0.4 & 242 & 0.7 \\
\hline 860 & 847 & 1.1 & 833 & 0.7 & 858 & 1.1 \\
\hline 1600 & 1631 & 1.8 & 1638 & 1.4 & 1656 & 1.8 \\
\hline 2100 & 2126 & 2.6 & 2156 & 1.9 & 2167 & 2.6 \\
\hline 2700 & 2676 & 5.3 & 2735 & 1.9 & 2734 & 5.3 \\
\hline 4100 & 4031 & 5.6 & 4141 & 3.0 & 4149 & 5.6 \\
\hline
\end{tabular}

Table 4. Values of $\chi_{\mathrm{obs}}^{2}$ and $\operatorname{Pr}\left\{\chi^{2}(v)>\chi_{\mathrm{obs}}^{2}\right\}$.

\begin{tabular}{lrr}
\hline Groove depth $(\mathrm{nm})$ & $\chi_{\text {obs }}^{2}$ & $\operatorname{Pr}\left\{\chi^{2}(v)>\chi_{\text {obs }}^{2}\right\}$ \\
\hline 100 & 9.156 & $10.30 \%$ \\
240 & 5.805 & $32.57 \%$ \\
860 & 3.717 & $44.57 \%$ \\
1600 & 2.248 & $81.39 \%$ \\
2100 & 5.727 & $33.37 \%$ \\
2700 & 3.169 & $67.39 \%$ \\
4100 & 11.009 & $5.12 \%$ \\
\hline
\end{tabular}

Despite the fact that the grooves were measured on different areas on the calibration standards, the achieved results revealed good uniformity within the standard's measurement areas, as well as good comparability between the measurement areas.

In table 1 sampling areas and sampling lengths are stated for each measuring instrument used. Scans performed with the AFM were $5 \mu \mathrm{m} \times 5 \mu \mathrm{m}$, whereas the areas or sampling lengths in the cases of other instruments used were significantly larger. Therefore, using the AFM the groove depth could not be measured in accordance with ISO 5436$1: 2000$. Using other instruments, with the exception of the ellipsometer, assessments of the groove depths were done as per ISO 5436-1 requirements.

Furthermore, a problem with the size of the calibration standards appeared during the AFM measurements. Namely, the samples are $50 \mathrm{~mm}$ in diameter and as such cannot be 


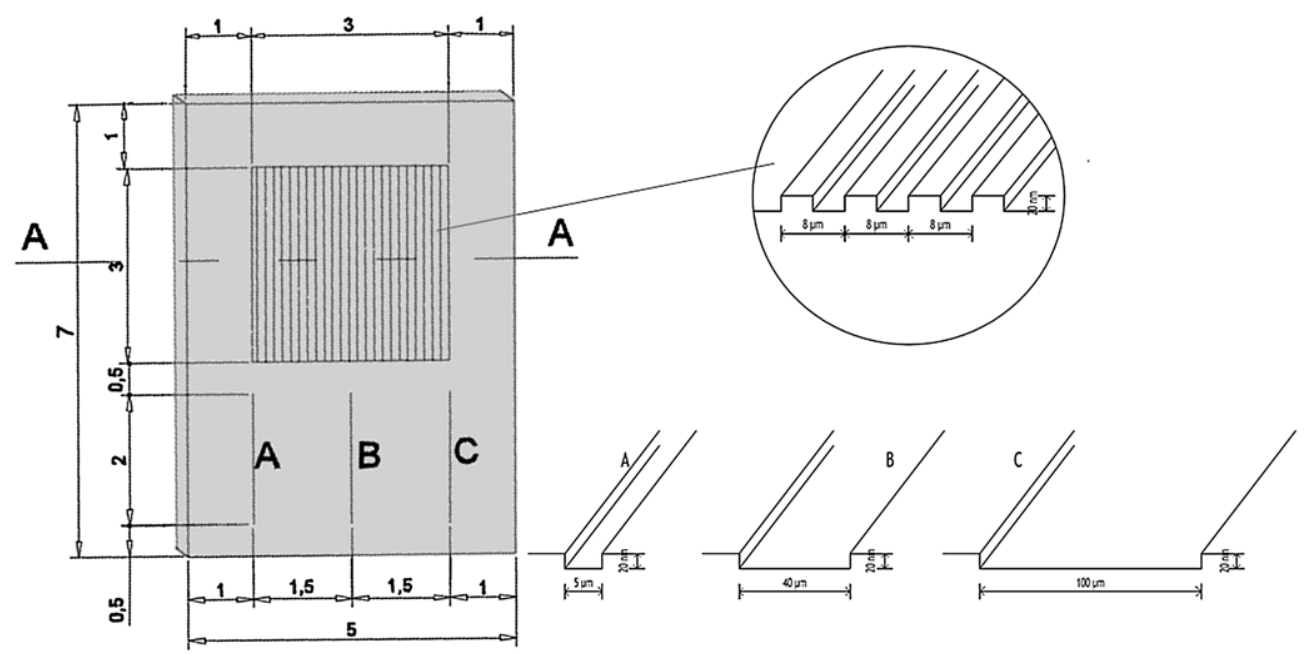

Figure 13. Design of new LFSB roughness reference standards.

measured by a majority of SPMs due to the size limitations of the setup of those instruments.

As was the case with the NANO2 comparison, the results obtained in this comparison were successful as well. In comparison to the instruments used in these two comparisons, in NANO2 SPMs were used more frequently. In this comparison measurements planned using some other SPMs were not made because of the large diameter of the calibration standard. In the NANO2 comparison, the size of the measured standards was $5 \mathrm{~mm} \times$ $5 \mathrm{~mm}$ ensuring their acceptance in all the available SPMs. As for the nominal value of the measured groove depths in this work they ranged from 100 up to $2700 \mathrm{~nm}$, as opposed to measured step heights from NANO2 that were in the range from 7 to $800 \mathrm{~nm}$ [7].

The outcome of the NANO2 comparison has served the participants to validate or to improve their instruments. As for the aim of this comparison, the obtained results and experience will serve in the development of a new roughness standard.

Although the results showed good comparability, a new model of reference standards is to be considered, for all the reasons discussed above. These new calibration standards will have two measurement areas to ensure the ability to measure the groove depths as well as 2D and 3D roughness parameters. One surface is a sequence of rectangular $\mathrm{SiO}_{2}$ grooves, while the second measurement area consists of three wide rectangular $\mathrm{SiO}_{2}$ grooves. Grooves with different lateral sizes are chosen so that the calibration standard could be measured by different types of instruments. The sizes of the probe dimensions were considered in the design of measurement areas. Both measuring surfaces of the calibration standard will have the same nominal value of the groove depth, thus ensuring a link between those measurement surfaces. This characteristic, as far as the authors know, makes them unique. Measurements are planned to be carried out in order to confirm the same assumed depths of the grooves with different widths.

The impact of the measured calibration standard in the uncertainty budget calculation is the one with the most influence. For this reason, reduction of the measurement area should be considered in order to help ensure better uniformity of standards measurement surfaces.

Since the LFSB has more than 20 years of good experience with $\mathrm{Si} / \mathrm{SiO}_{2}$ as a material for standard's structures, and the fact that today silicon is the most used material for calibration standards in the field of dimensional nanometrology [5, 6], new LFSB roughness standards will also be made from silicon.

In figure 13 the design of new LFSB roughness reference standards is presented.

Due to the transparency and electrical non-conductivity of the $\mathrm{SiO}_{2}$ layer, the $\mathrm{Si} / \mathrm{SiO}_{2}$ structures will be coated with a thin metallic layer which will provide conditions for optical measurements and measurements that require conductivity of the measurement surface.

Therefore the selected layer must have the following properties:

- excellent mechanical properties,

- good adhesion,

- ability to maintain the geometry of the primary structure of $\mathrm{Si} / \mathrm{SiO}_{2}$ (same level of deviation from parallelism and flatness),

- required optical properties and

- electrical conductivity.

As far as the authors are aware, the above-discussed new design of calibration standards makes them unique. Namely, as for the surface with a sequence of rectangular $\mathrm{SiO}_{2}$ grooves there are commercially available standards but uncoated. Those standards are usually intended to be used by AFMs but they cannot be measured by interferometry or measurements that require electrical conductivity of the measured surface. As for groove depths, i.e. step heights with different widths that can be measured by a variety of different measurement methods, there are, of course, the standards that were measured in the NANO2 intercomparison.

But the fact that the new design of the calibration standard discussed here has two measurement surfaces with the same 
nominal value of groove depths, thus ensuring a link between those measurement surfaces, makes those standards unique. Furthermore, coating of those standards will provide all required conditions on the measurement surface in order to be measured with optical instruments, stylus instruments, SEMs, AFMs and STMs.

The calibration standards are partially produced, and the LFSB has begun the research on the standards' measuring properties.

\section{Conclusion}

With the intensive progress in nanotechnology, new measuring instruments with the possibility of sub-nano-resolution have been developed. Consequently problems with the reference standards in the nano area have appeared.

Furthermore, in the area of nanometrology particular problems represent the difficulties in ensuring the reproducibility of the measurement results achieved by different measuring devices (methods). Therefore, it was decided to explore the limitations of measurement methods in the procedure of groove depth measurements on the LFSB roughness reference standards. In order to include as many measuring instruments in that research as possible, the LFSB launched EURAMET Project 1012 'Limitations of methods for measuring the depth of the groove'.

The obtained results showed overall good agreement within the declared levels of measurement uncertainties, with the exception of the results obtained with the AFM. However, if we look at the measurement areas with respect to the applied measurement methods, one can see that they are formed by different technologies. Therefore, there is a question of the influence of various measurement surfaces on the measurement results obtained with different measuring instruments.

Even though the grooves were measured on different areas on the standard, the obtained results showed good uniformity within the measurement areas, as well as good comparability between the standard's measurement areas. The results obtained using the AFM, in comparison to the results obtained using other measuring instruments, showed a linear decrement with increasing nominal values of the measured groove depths. A detailed analysis of the potential causes for the observed deviation in the results obtained using the AFM is in progress.

In addition, a problem with the size of the calibration standards appeared during the AFM measurements. Since the LFSB standards are $50 \mathrm{~mm}$ in diameter they were just at the borderline to be mounted on the AFM. Specifically, the capability to accept the size of calibration specimens was the crucial reason why they were not measured using other available SPMs.
Although the results showed good comparability, a new model of reference standard is to be considered, for all the reasons discussed above. That calibration standard would have a single measurement surface whatever the measurement method used. That way, measurements on that single, unique surface would indicate only the differences due to the used measurement methods, i.e. devices. This new LFSB roughness reference standard is partially produced. After complete physical realization of the standard, the expected measuring features will be analyzed experimentally. In addition, comparative measurements of the groove depth on these new LFSB standards will be carried out using different measuring devices (methods) in order to determine the level of repeatability and reproducibility of the measurement results. Moreover, research on the suitability of the surface with repetitive grooves for the reproduction of roughness parameters in the field of nanometrology will be carried out.

\section{References}

[1] ISO 2000 Geometrical product specifications (GPS)—surface texture: profile method. Measurement standards: part 1. Material measures ISO 5436-1:2000

[2] Mahović S 1985 Doprinos baždarenju etalona za podešavanje uređaja za ispitivanje hrapavosti tehničkih površina Dissertation University of Zagreb (in Croatian)

[3] ISO 1997 Geometrical product specifications (GPS)—surface texture: profile method. Terms, definitions and surface texture parameters ISO 4287:1997

[4] Cox M G 2002 The evaluation of key comparison data Metrologia 39589

[5] Review of Standards 2009 http://nanoscale.de/standards/techniques.htm

[6] Review of Standards 2009 http://nanoscale.de/standards/design.htm

[7] Koenders L et al 2003 Comparison on nanometrology: nano 2-step height Metrologia 4004001

[8] Leach R K et al 2010 Consultation on a European Strategy for Nanometrology

[9] Working Group on Dimensional Metrology 2002 CCL/WGDM/02-55 http://www.bipm.org/utils/common/pdf/WGDM2002.pdf

[10] Wilkening G 2009 Atomic scale metrology in the bridge from top down to bottom up methods www.ptb.de/en/org/5/52/index.htm

[11] Bhushan B (ed) 2007 Springer Handbook of Nano-Technology 2nd edn (Berlin: Springer)

[12] European Nanotechnology Gateway 2006 Eighth Nanoforum Report Nanometrology

[13] JCGM 2008 Evaluation of measurement data-guide to the expression of uncertainty in measurement JCGM 100:2008

[14] Koenders L, Dziomba T, Thomsen-Schmidt P and Wilkening G 2005 Standards for the calibration of instruments for dimensional nanometrology Nanoscale Calibration Standards and Methods (Weinheim: Wiley-VCH)

[15] Hansen H N, Carneiro K, Haitjema H and De Chiffre L 2006 Dimensional micro and nano metrology Ann. CIRP 55 721-43 